\title{
Aerodynamic Investigation of Guide Vane Configurations Downstream a Rotating Detonation Combustor
}

\author{
Majid Asli* \\ Graduate Research Assistant \\ in Gas Turbine Processes, \\ Technical University of Berlin \\ Berlin, 10623, Germany \\ Email: asli@campus.tu-berlin.de

\section{Christian Oliver Paschereit \\ Professor \\ Chair of Fluid Dynamics, Technical University of Berlin \\ Berlin, 10623, Germany} \\ Email: oliver.paschereit@tu-berlin.de
}

Chair of Unsteady Thermodynamics Chair of Unsteady Thermodynamics

\section{Panagiotis Stathopoulos}

Professor

in Gas Turbine Processes,

Technical University of Berlin

Berlin, 10623, Germany

Email: stathopoulos@tu-berlin.de

\begin{abstract}
Any outlet restriction downstream of Pressure Gain Combustion (PGC), such as turbine blades, affects its flow field and may cause additional thermodynamic losses. The unsteadiness in the form of pressure, temperature and velocity vector fluctuations has a negative impact on the operation of conventional turbines. Additionally, experimental measurements and data acquisition present researchers with challenges that have to do mostly with the high temperature exhaust of PGC and the high frequency of its operation. Nevertheless, numerical simulations can provide important insights into PGC exhaust flow and its interaction with turbine blades. In this paper, a Rotating Detonation Combustor (RDC) and a row of nozzle guide vanes have been modeled based on the data from literature and an available experimental setup. URANS simulations were done for five guide vane
\end{abstract}


configurations with different geometrical parameters to investigate the effect of solidity and blade type representing different outlet restrictions on the RDC exhaust flow. The results analyzed the connection between total pressure loss and the vanes solidity and thickness to chord ratio. It is observed that more than $57 \%$ of the upstream velocity angle fluctuation amplitude was damped by the vanes. Furthermore, the area reduction was found to be the significant driving factor for damping the velocity angle fluctuations, whether in the form of solidity or thickness on chord ratio increment. This RDC exhaust flow investigation is an important primary step from a turbomachinery standpoint, which provided details of blade behavior in such an unsteady flow field.

\section{NOMENCLATURE}

$\bar{A}$ Corrected amplitude.

M Mach number.

$\mathrm{N}$ Number of blade.

Pt Total pressure.

PDC Pulsed detonation combustion.

PGC Pressure gain combustion.

RDC Rotating detonation combustion.

Tp Time period.

$\mathrm{T}_{\mathrm{t}}$ Total temperature.

c Chord length.

s Second.

t Time.

$\alpha$ Velocity angle.

$\sigma$ Solidity (chord/space).

$\tau$ Thickness to chord ratio (thickness/chord).

$\omega$ Total pressure loss coefficient. 
Journal of Engineering for Gas Turbines and Power

\section{INTRODUCTION}

One of the fastest growing sources of greenhouse gas emissions is aviation. Direct emissions from aviation account for about 3\% of the EU's total greenhouse gas emissions and more than $2 \%$ of global emissions. If global aviation were a country, it would rank in the top 10 emitters, reported by European commission. Global international aviation emissions by 2050 could increase up to $700 \%$ compared to 2005 , if no measures are taken [1]. On the other hand, the growing number of air passengers reported by International Civil Aviation Organisation (ICAO) [1] and the related tourism market encourage aircraft manufacturers to have greater impact in the field. This is not only the case for aviation, but also for land-based applications of gas turbines for energy production. Although harvesting renewable energy is expanding, the capability of gas turbines for delivering energy and power reserve, keep them relevant in global energy markets. Therefore, gas turbine manufacturers are continuously seeking to increase efficiency and lower emissions.

To date, many efforts have been done to increase the existing gas turbine efficiency by improving component performance. In this regard, these components are so technologically mature that any effort to achieve higher efficiency will not increase the whole gas turbine efficiency above half percent [2-4]. Therefore, reconfiguring gas turbines by introducing innovative cycles is one of the most crucial options left to make a step-change in efficiency. Such a new configuration can be achieved through the Humphrey or the ZND cycle. In these cycles, constant pressure combustion is replaced with pressure gain combustion, which leads to a lower entropy generation. The Humphrey cycle models gas turbines with ideal constant volume combustion. The ZND cycle models the application of detonative combustion in gas turbines [5]. Pulsed and Rotating Detonation Combustion are the two well-known types of detonative PGC. The higher frequency and self-sustained detonation waves of the latter make it the most suitable for future integration in continuously operating turbomachines [6].

One of the early efforts in turbine and PGC integration was done by Schauer et al. [7], who experimentally showed the feasibility of PDC and its operation with turbomachinery. They could sustain 25 minute continuous run of a PDC driving a radial turbine. Rasheed et al. [8,9] tested a multi-tube PDC together with a single stage axial turbine, and a by-pass flow of air that mixed with 
the PDC exhaust before its entrance in the turbine. They showed that for their specific case the turbine isentropic efficiency was effectively the same with the one under steady operation. The feasibility of RDC and gas turbine integration has been also recently demonstrated. Wolański [10] investigated the integration of an RDC into a GTD-350 helicopter engine. He found that the engine can be operated with lean mixtures and that the specific fuel consumption was $5 \%$ to $7 \%$ lower than for the conventional system. In a similar work, Naples et al. [11] developed an RDC and successfully deployed it into a T63 gas turbine. They achieved 20 minutes of damage-free operation. In spite of observing substantially higher unsteadiness generated by the RDC, they concluded that this did not affect turbine efficiency significantly [12]. Rhee et al. [13] replaced the combustor of a commercial jet engine by a newly designed RDC. They tested the engine and measured the temperature at turbine inlet and exit plane and also turbine rotational speed.

Despite the lower entropy generation of pressure gain combustion, there are some major challenges for getting this type of combustor integrated in a gas turbine. The inherent strong unsteady exhaust flow of PGC make it unfitting for conventional turbine expanders. Tellefson [14] performed RDC-nozzle and axial turbine testing. He concluded that using a nozzle at the RDC outlet can experimentally simulate the effect of the turbine presence on the RDC operation. Rankin et al. [15] studied the behavior of a convergent divergent nozzle at RDC downstream. They demonstrated that the combination of a conical center body and converging-diverging nozzle could be a possible solution to alleviate RDC unsteadiness. Turbine integration with RDC has been studied at Purdue University as well. Braun et al. [16] studied different nozzle geometries at RDC outlet to assess nozzle performance with respect to the inlet flow fluctuations. A smooth divergent profile has delivered the highest flow momentum increase and the strongest damping of the Mach number distribution. These high Mach number fluctuations and the respective incidence angle variation are still an challenge for the operation axial turbines. The operation of a supersonic turbine exposed to RDC was studied numerically by Liu et al. [17]. Total pressure loss was computed and it was concluded that the leading edge shock wave is the dominant loss source. Braun et al. [18] investigated the influence of an integrated nozzle and supersonic axial turbine with an RDC. They observed that flow angle fluctuations could not be reduced through the nozzle. The flow turning, 
pressure loss and the damping effect of the supersonic stator vanes were also evaluated by them numerically.

Recently, an instrumented guide vane has been set up to characterize RDC flow by Bach et al. [19] at TU Berlin. The aim was to address the effect of RDC outlet restriction on combustion through the combined effects of elevated initial reactant pressure and reflected shocks interacting with the detonation wave. They also performed pressure measurements upstream and downstream of the vanes to measure the average pressure loss through the vanes. The compact geometry, rapid and high temperature flow limit the measurement and visualization capabilities. Furthermore, the presence of measuring probes mounted on the blades can cause uncertainties in the acquired experimental data. Therefore, numerical analysis can be a promising tool to understand the flow field around the vanes. Asli et al. [20] studied the same geometry numerically to look into the details of the vanes behavior and compared the measured data with the experiments. Following this research, the RDC configuration with different blade types has been modeled numerically in the current work. Here, the objective is to evaluate how different vane types and different blade solidities affect the flow in the turbine blade row. Pressure loss has been computed and the damping role of the vanes has been investigated in detail.

\section{MODEL DESCRIPTION}

\section{RDC Configuration}

The RDC setup is a radially inward configuration for oxidizer injection. In this configuration, hydrogen is injected trough 100 equally spaced holes, while the oxidizer is injected trough a circumferential slot. The annulus has an outlet diameter of $90 \mathrm{~mm}$, a passage width of $7.6 \mathrm{~mm}$ and its axial length is $114 \mathrm{~mm}$. According to the scope of research, RDC exhaust flow at the outlet of the RDC annulus is considered as the non-reactive working fluid. Additionally, the annulus width is much shorter than axial length and circumference of the domain. The dominant flow phenomena and related fluctuations within the RDC occur in circumferential and axial directions rather than radial direction. Therefore, in this study the annulus radial height is neglected and the three-dimensional physics of the RDC exhaust channel is unwrapped and reduced in a 


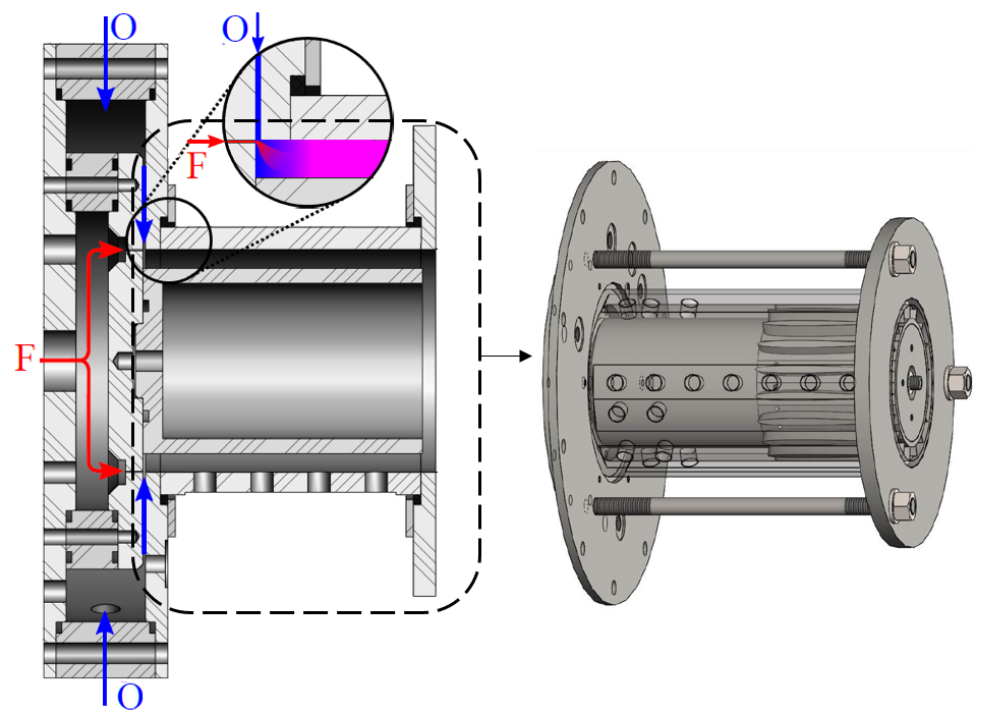

Fig. 1: Schematics of the modeled RDC annulus with a nozzle blade row [19].

two-dimensional domain to significantly reduce computational cost. The experimental model and the vanes mounted on the RDC annulus is shown in Fig. 1. The symmetrical blade profile of NACA0006 is selected to be modeled at the RDC outlet to study effect of presence of a general simple guide vane on RDC exhaust flow. This profile type is a simplification of real geometry to obtain a better understanding of the flow physics and investigate effect of geometrical parameters on the RDC flow field. The same configuration has been tested experimentally at TU Berlin [19].

\section{Numerical Setting}

Unsteady Reynolds-averaged Navier Stokes (URANS) simulations were carried out using ANSYS FLUENT density-based solver, which has been widely used for similar problems in turbomachinery $[17,21,22]$. Second order discretization and the SIMPLE scheme for pressure-velocity coupling were applied. The transition-shear stress transport model, based on Wilcox $k-\omega$ turbulence model proposed by Menter [23] was utilized. This two-equations eddy-viscosity model combines advantages of both $k-\omega$ in the inner region of boundary layer and $k-\varepsilon$ in the free stream flow. Therefore, it performs well in both near and far walls domains, as well as in separated flow regions which are probable in the present study because RDC exhaust flow angle is highly fluctuating and can cause flow separation on the blades. The flow specifications as the domain inlet 


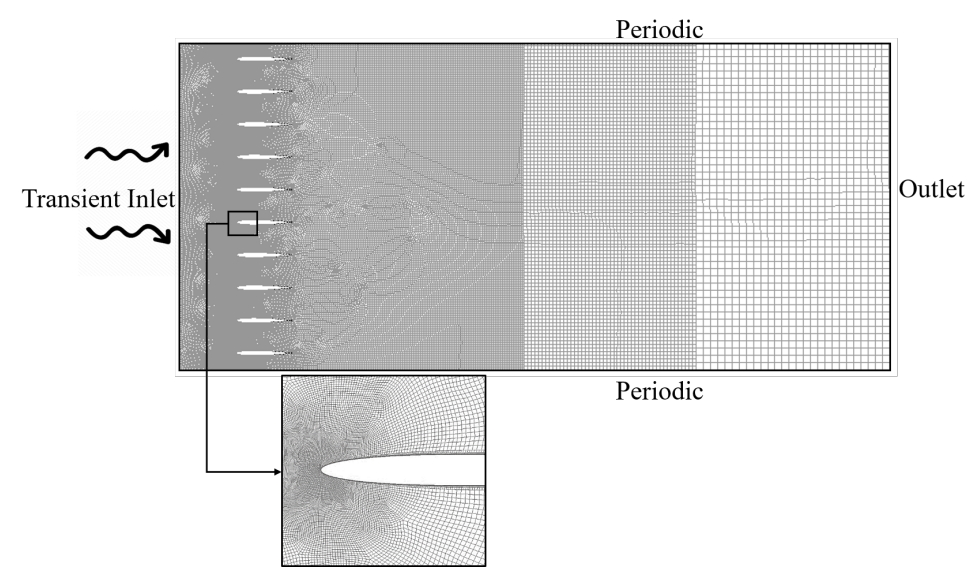

Fig. 2: Computational domain and grid around the blades.

boundary conditions will be discussed later in detail. The working fluid is considered to be a mixture of nitrogen $\left(\mathrm{N}_{2}\right)$ and water vapor $\left(\mathrm{H}_{2} \mathrm{O}\right)$ with mass fractions of 0.745 and 0.255 respectively that are products of Hydrogen-air combustion. The mixture is assumed to be a perfect gas thermally and calorically. Convergence criteria of the numerical solutions for each time step is set at $10^{-6}$ for all the residuals.

The computational domain, which is the same for all the simulations, is formed to simulate the two dimensional unwrapped RDC exhaust annulus at mid-span radius. This creates a rectangular domain that extends one blade chord length upstream of the blade leading edge and ten blade chords downstream the blade trailing edge to let the flow developed within the computational domain [24]. The domain containing the mesh is depicted in Fig. 2. The mesh is dense enough in areas of high curvature around the blades using a curvature and proximity algorithm in order to capture the geometry and boundary layer. The dimensionless wall distance $\left(y^{+}\right)$is kept bellow 1 to ensure a good resolution of the near wall regions. This is done by refining the mesh during simulation. Additionally, as the flow property gradients are high at the inlet boundary, the mesh was refined up to the 4 chord downstream of the blades during the simulations to achieve the optimum convergence time.

Four mesh configurations with different densities have been generated to evaluate effect of grid size on the results. Simulations were done for the case with 15 blades of NACA0006 profile having $150 \mathrm{k}, 170 \mathrm{k}, 190 \mathrm{k}$ and $250 \mathrm{k}$ nodes. The total pressure loss coefficient defined as $\omega=1-P_{t} / P_{t, \text { inlet }}$ 


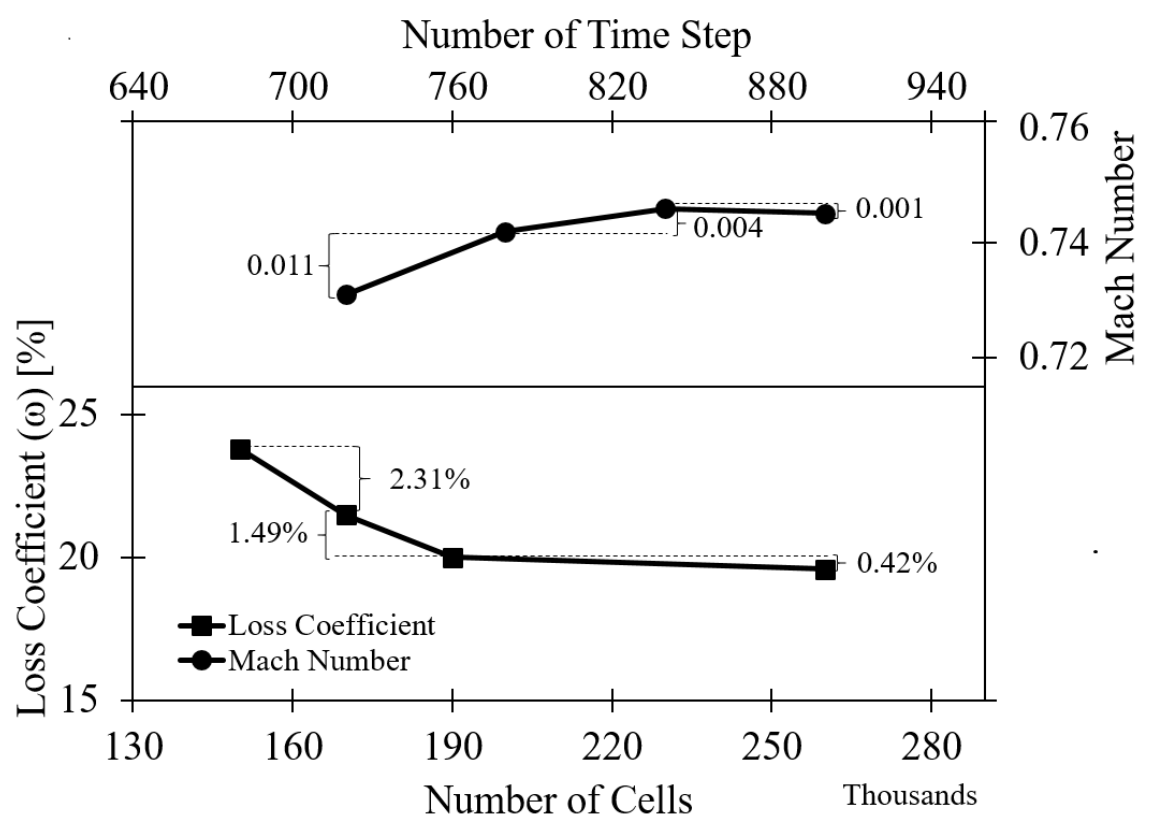

Fig. 3: Effect of grid size and time step on total pressure loss coefficient and mass averaged Mach number at $0.2 \mathrm{c}$ upstream of the vanes.

has been calculated between 0.2c upstream and $2 \mathrm{c}$ downstream of the vanes. According to Fig. 3, the simulation results for the latter two grids exhibit only $0.42 \%$ difference in total pressure loss coefficient along the vanes. Therefore, the grid density with $190 \mathrm{~K}$ nodes was selected for the simulations of the present research.

In order to capture all the flow features in an unsteady simulation, the global time step must be chosen small enough. An appropriate time step value depends very much on the flow fluctuations. A time step sensitivity analysis was performed previously for similar flows [20,25]. However, for the current research four different time steps ranging from 720 to 900 are considered to find the optimum value. Mass averaged values of Mach number at $0.2 \mathrm{c}$ upstream of the vanes are calculated for the case with 15 blades of NACA0006. According to Fig. 3, the mass averaged Mach number is increasing by increasing time step up to 840 and then decreases slightly for the time step of 900 . The difference between the two higher time steps is 0.001 , which is much lower than that of the other time steps. Therefore, the suitable time step for the simulations in the present study is chosen to be 840 times smaller than the RDC time period.

In the present numerical simulations, the inlet flow boundary condition must be supplied by the GTP-20-1512 


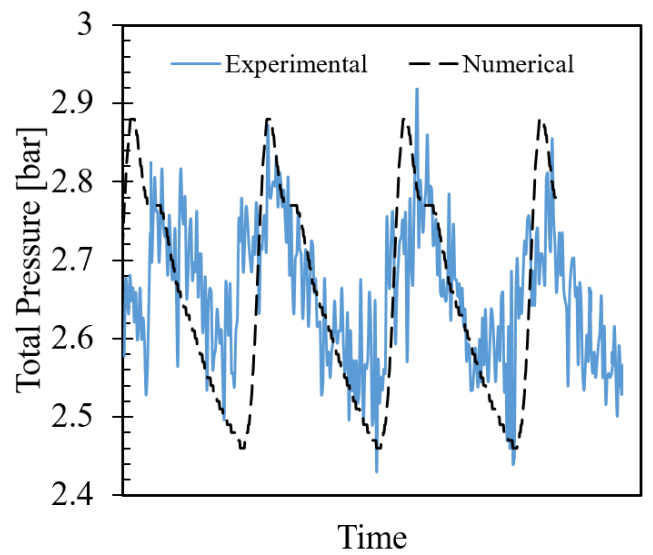

(a) Blade row upstream

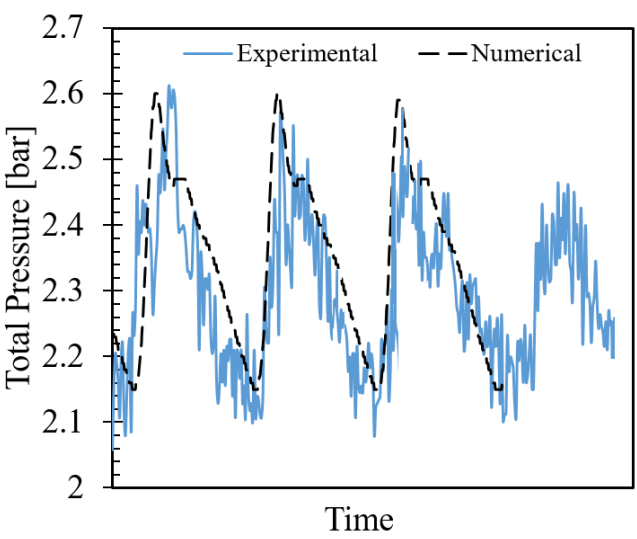

(b) Blade row downstream

Fig. 4: Total pressure distribution at upstream and downstream of the blade row.

RDC exhaust flow conditions. Pressure measurements in the RDC setup of the TU Berlin reported time averaged values that indicated a peak total pressure of 2.9 bar at the blade upstream [19]. This value shows that the experimental diagnostics have difficulties to acquire time-resolved measurements, since the peak pressure values are expected to be in the order of 10 bar [26]. However, the average measured values were quite promising as reported. The RDC annulus equipped with NACA0006 profile vanes mounted at the outlet has been numerically simulated [20]. This vane configuration will be introduced as profile C.1 later in the paper. The numerical results are compared with the experimental ones to verify the numerical method accuracy. In Fig. 4, total pressure distributions at upstream and downstream of the blade row are plotted. The numerically obtained pressure data reported here is measured exactly at the same locations as in the experimental setup. Based on the two curves of experiments and numerical simulation, an acceptable matching for total pressure results around the vanes is observed. This shows that the total pressure loss caused by the blade row in the experimental setup was accurately simulated. The consistency between the two set of results confirmed the validity of numerical simulation for the RDC exhaust flow.

\section{Boundary Conditions}

The current work uses the simulated RDC flow characteristics provided by Schwer et al. [27] as the inlet boundary condition of the domain. The inlet boundary represents two rotating waves 


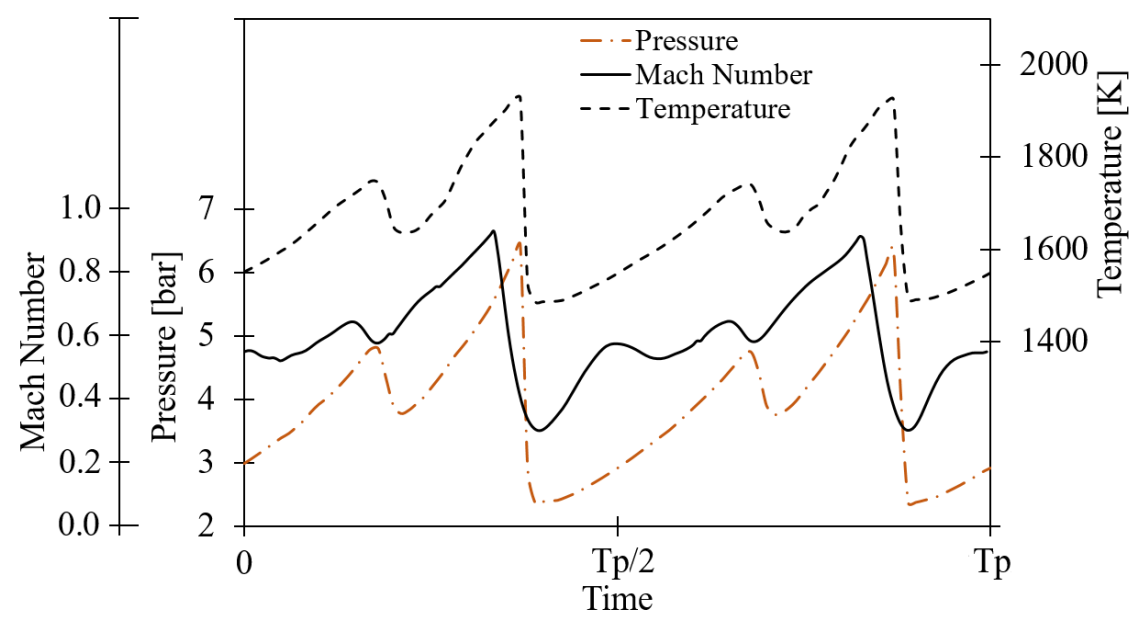

Fig. 5: RDC exhaust flow properties considered as the inlet condition.

traveling around the annulus. This wave mode provides a pressure distribution with $\sim 7$ bar peak and a static temperature ranging from $1500 \mathrm{~K}$ to $2000 \mathrm{~K}$ as shown in Fig. 5. The frequency of the fluctuation is $7 \mathrm{kHz}$ and the flow angle variation in blade to blade surface is approximately \pm 40 degree with the mean value of -10.5 degree. The outlet boundary for the computational domain is considered as the pressure far field type and the two sides are unified as a periodic boundary to ensure periodicity and shape the unrolled presentation of the cylindrical annulus (see Fig. 2).

The aforementioned settings are the same for the five cases listed in Tab. 1. Different solidities have been achieved by changing blade numbers from 10 to 15 and 20 for case C.1 to case C.3 respectively. The solidity values are selected within the conventional range offered by AinleyMathieson correlation [28]. The two other cases with different blade types have been considered to evaluate effect of blade thickness while having the same solidity values and blade numbers. The numerical calculations have been done using eight Intel(R) CPUs at $4.00 \mathrm{GHz}$ with 4 cores and 32 GB of memory in parallel. The mean CPU time for each case was 25 hours to achieve convergence. 
Table 1: Blade configuration specifications at RDC downstream.

\begin{tabular}{cccccc}
\hline \hline Case Nr. & Profile Type & $\sigma$ & $\tau$ & $\mathrm{N}$ & Area Reduction \\
\hline C.1 & NACA0006 & 1.76 & $6 \%$ & 10 & $10.55 \%$ \\
C.2 & NACA0006 & 2.64 & $6 \%$ & 15 & $15.83 \%$ \\
C.3 & NACA0006 & 3.52 & $6 \%$ & 20 & $21.10 \%$ \\
C.4 & NACA0009 & 1.76 & $9 \%$ & 10 & $15.83 \%$ \\
C.5 & NACA0012 & 1.76 & $12 \%$ & 10 & $21.10 \%$ \\
\hline
\end{tabular}

\section{RESULTS AND DISCUSSION}

\section{Pressure Loss}

The simulation of the RDC exhaust flow passing through the guide vanes entails a transient phase before reaching periodically steady operation in the entire computational domain. The main difference of the two modes is the presence of specific shock waves in transient operation, which are not present in the steady periodical operation. The flow features of both operational phases are discussed in this section.

To evaluate the impact of different blade configurations on the blade total pressure loss, the mass averaged total pressure has been computed at $0.2 \mathrm{c}$ and $2 \mathrm{c}$ downstream of the vanes. The total pressure loss coefficient has been calculated for each case. Figure 6 shows its values averaged in one combustor period with pattern filled bars. In the transient operational phase, an increase of the blades number from 10 to 15 and then to 20 leads to higher total pressure loss coefficients from 0.176 to 0.201 and then to 0.224 , respectively. Additionally, the loss coefficients for different thickness on chord ratio corresponding to the cases C.1, C.4 and C.5 are 0.176, 0.190 and 0.212 , respectively. Figure $7 \mathrm{a}$ and Fig. $7 \mathrm{~b}$ indicate the instantaneous contours of Mach number and density for C.4, as a sample, in two different time instances. According to the RDC exhaust flow, there are two rotating waves that cause two symmetric patterns traveling circumferentially. In this regard, half of the time period is considered in Fig. 7 and the two equal time intervals of the flow field are depicted. The contours pattern reveals that the fluctuating flow is subsonic up to the vane row. Flow Mach number at the passage inlet location ranges 0.69-0.97, 0.33-0.86, 0.62-0.96 
and $0.46-0.98$ for each of the four cases C.1, C.3, C.4 and C.5 respectively. In this subsonic flow regime, the presence of vanes may affect the combustion process, which is not in the scope of this study. The flow Mach number subsequently increases when the flow enters the vane passages and it continues to accelerate up to the vanes trailing edge. There is a sharp deceleration to supersonic Mach numbers at around one chord length downstream of the vanes, where a rather great increase in density exists. This confirms the presence of shock waves downstream of the vanes, which is an important source of total pressure loss indicated in Fig. 6 for the transient operational phase in addition to the vanes profile loss. The compression waves are present in the flow field of all the other configurations not depicted here. These shock waves are transferred downstream towards the outlet of the computational domain. Velocity vectors are zoomed-in around two sample blades and shown inside the contours of Mach number as well. It shows that velocity vectors are quite fluctuating at upstream of the vanes and where hitting the vanes leading edge. Thereafter, the velocity vectors are getting straighter while passing through the vane passages.

The flow field reaches periodically steady condition when the shock waves move out from the domain outlet. The periodically steady operating flow field is shown in Fig. 7c and Fig. 7d in two different time instants. Total pressure loss has been calculated at $0.2 \mathrm{c}$ downstream of the vanes for all the cases and the related coefficients are indicated in Fig. 6 with blue filled bars. The loss coefficient in steady operation, which represents profile loss, is decreasing from 0.06 to 0.029 and then to 0.019 when the solidity is increased from 1.76 to 2.64 and then to 3.52 , respectively. Additionally, the loss coefficients of C.1, C.4 and C.5 are $0.06,0.053$ and 0.022 each. These trends are not consistent with the conventional profile loss correlation of Ainley-Mathieson and the empirical model by Aungier [28]. Based on the conventional loss correlation, higher solidity should result in higher loss coefficients. The inconsistency arises due to the flow unsteadiness with high amplitude of flow angle fluctuation in RDC exhaust flow. Furthermore, comparing loss coefficient of the periodically steady operation with the transient one shows that the share of shock loss in total amount of loss in transient operation is very high with respect to the profile loss. Higher solidity and higher area reduction cause higher Mach number downstream of the vanes and hence stronger shock waves and higher shock loss coefficients marked in Fig. 6. 


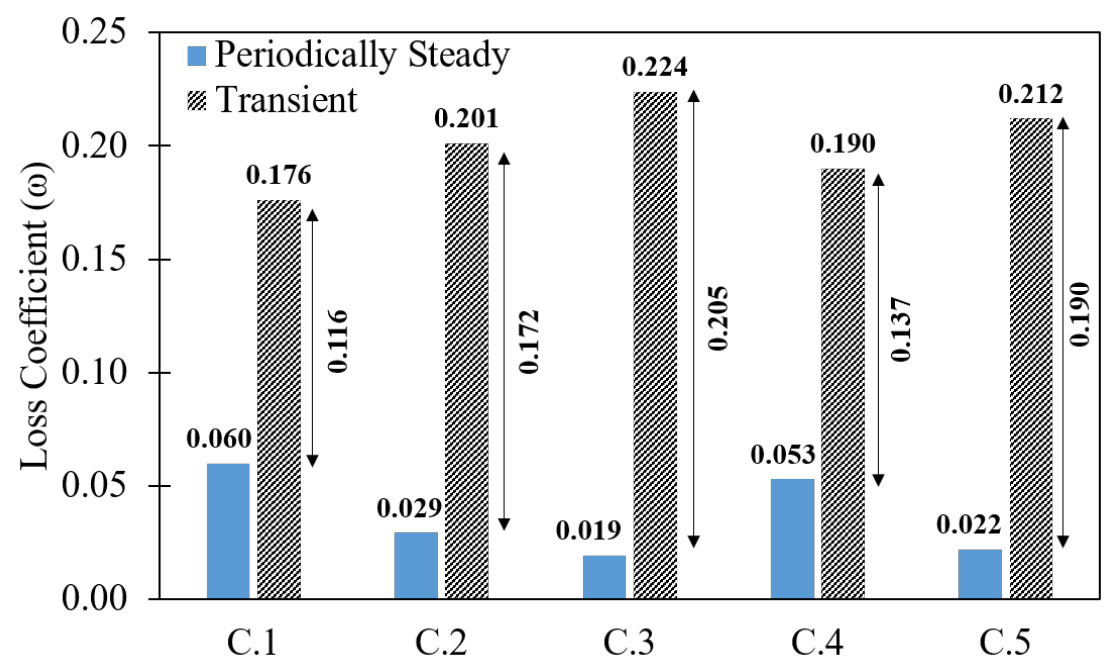

Fig. 6: Total pressure loss coefficient.

\section{Passage Chocking}

Chocking is likely to happen in turbine blades and fixes the reduced mass flow. To evaluate the flow inside the vanes, the Mach number on the centrally located line between two adjacent blades is measured during a whole RDC period. The locations where sonic Mach number is observed on this line are captured and plotted for the five cases within one period as displayed in Fig. 8. The axial location numbers are described graphically in Fig. 8a which are equally $(12.5 \% \mathrm{c})$ distributed on the center line of the vane passage from leading edge to trailing edge. The vane throat is located at 30\% chord for the cases C.1, C.2, C.3 and C5 and at 33\% chord for case C.4. If the flow field would have been steady, the maximum Mach number or sonic condition would have been expected at the throat location in each case (marked with dashed line in Fig. 8). However, the sonic Mach number location changes within an RDC period. The respective locations along the centerline are different for each case. A comparison of Fig. 8a with Fig. 8b and Fig. 8c shows that the higher solidity moves the point in which the sonic Mach number is reached downstream with shorter range of sonic Mach number locations. Additionally, although the two cases of C.3 and C.5 have the same area reduction, C.3 exhibits shorter range of sonic Mach number locations, mostly due to its higher solidity. By drawing a vertical line in the plots, it can be seen that each location experiences sonic condition four times within one time period. This means that the fluctuating 


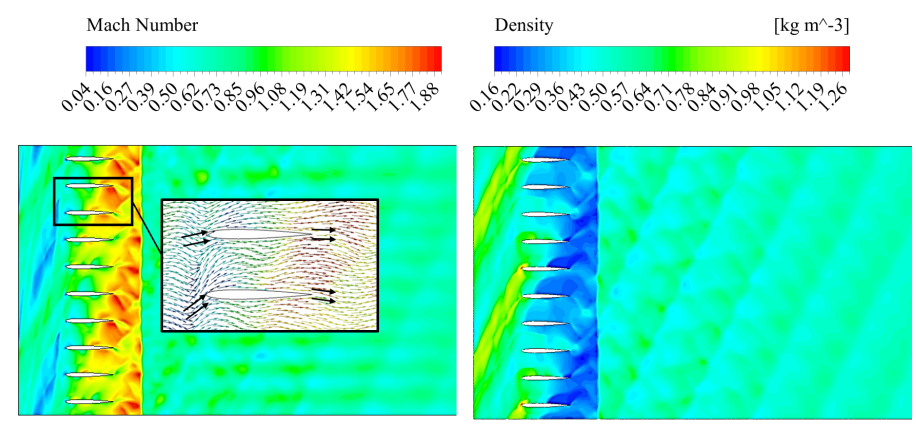

(a) Transient operation at $\mathrm{t}=\mathrm{Tp}$

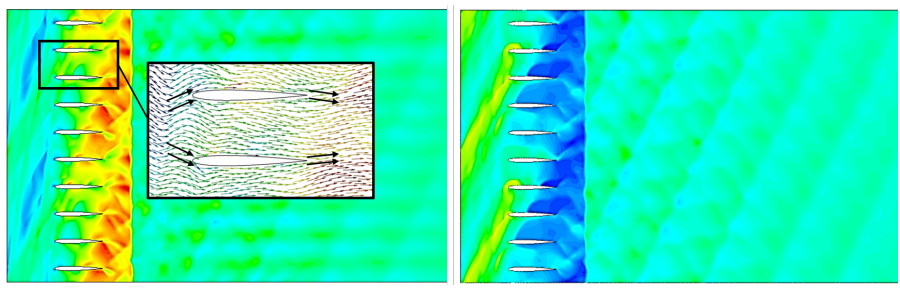

(b) Transient operation at $\mathrm{t}=\mathrm{Tp}+1 / 4 \mathrm{Tp}$

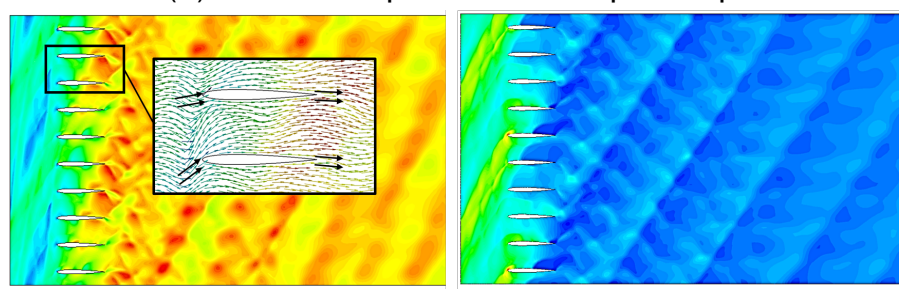

(c) Periodically steady operation at $\mathrm{t}=\mathrm{Tp}$

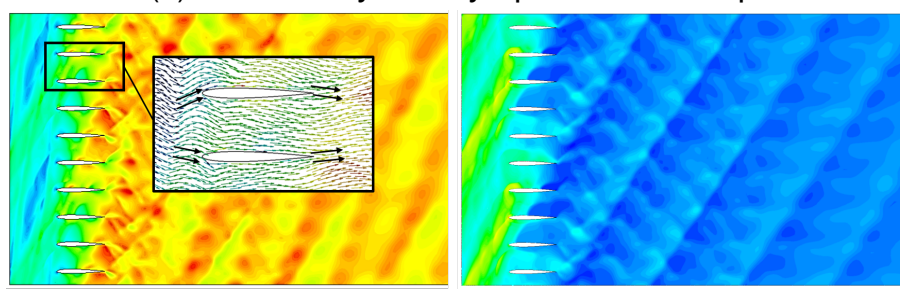

(d) Periodically steady operation at $\mathrm{t}=\mathrm{Tp}+1 / 4 \mathrm{Tp}$

Fig. 7: Instantaneous contours of Mach number (left) and density (right) for C.4.

exhaust flow of the RDC creates supersonic flow conditions when passing through the vanes over the entire RDC period. The Mach number distribution inside the vane passage of C.5 is shown in Fig. 8f. It indicates that the flow reaches the supersonic regime while exiting the vane passage. The Mach number at the vane passage outlet is in the range of 1.28-1.64, 1.29-1.82, 1.31-1.91, 1.45-1.76 and 1.41-1.88 for the cases C.1 to C.5 respectively. 


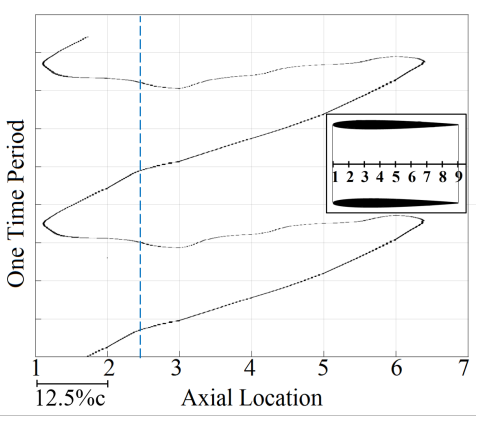

(a) C.1

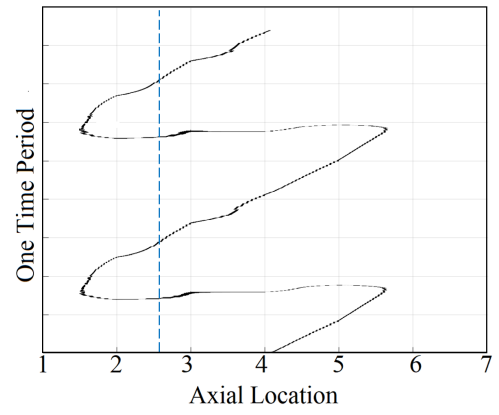

(d) C.4

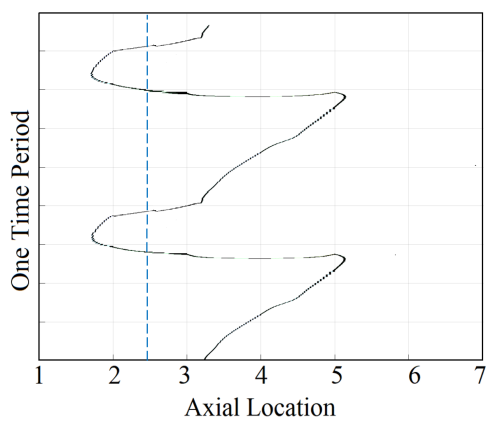

(b) C.2

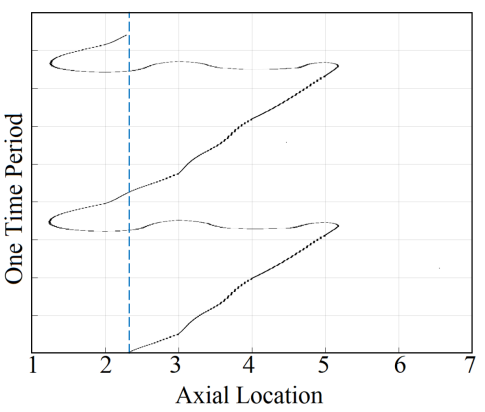

(e) C.5

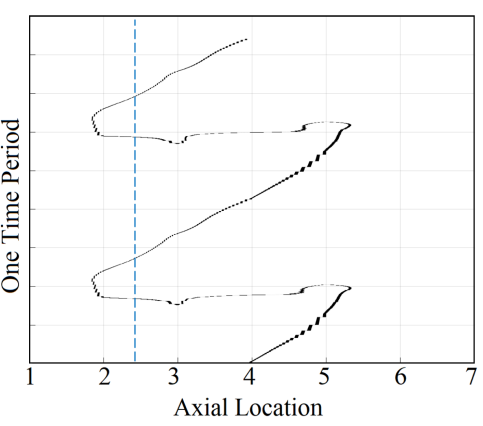

(c) C.3

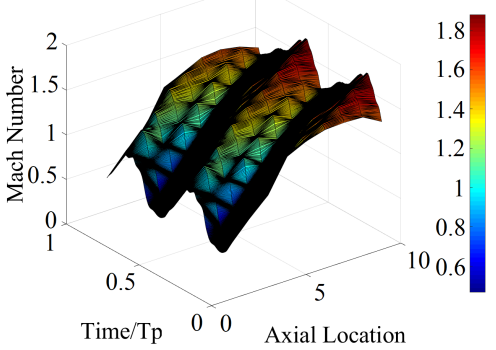

(f) C.5

Fig. 8: Sonic condition inside the blade passages (a-e) and Mach number distribution for C.5 (f).

\section{Flow Unsteadiness Damping}

One of the most important parameters affecting the flow within turbomachinery blade rows is the flow incidence angle. Theoretically, blades are designed to work in a defined (design) incidence angle to reduce aerodynamic losses. Any deviation from the design value causes considerable aerodynamic losses. For the present case study, the inherent flow velocity angle fluctuations make the study of their effect on the flow within the rows necessary. The time trace corrected velocity angle, defined as $\bar{\alpha}=\alpha / \alpha_{\text {average } @ \text { upstream }}$ at 20\%c downstream of the vanes, is plotted for all cases in one RDC period in Fig. 9a. The corrected flow angle at $20 \%$ c upstream of the vanes is marked by a dashed line, which is almost the same for all the cases. The corrected velocity angle amplitude, defined as $\overline{A_{\alpha}}=\overline{\alpha_{\max }}-\overline{\alpha_{\min }}$, is $2.52,1.19,0.83,2.24$ and 1.03 for $\mathrm{C} .1$ to C.5 respectively as tabulated in Tab. 2 . By considering its value at the upstream location 5.85 , it can be stated that the amplitude of the velocity angle fluctuation is reduced by more than $57 \%$. By increasing solidity from 1.76 to 3.52 (in C.1 and C.3), the velocity angle amplitude is reduced even more (by 86\%). At the same time, an increase of the thickness to chord ratio from 6 to 12 , 
Table 2: Corrected velocity angle amplitude at $20 \%$ c downstream.

\begin{tabular}{cccccc}
\hline \hline & C.1 & C.2 & C.3 & C.4 & C.5 \\
\hline$\overline{A_{\alpha}}$ & 2.52 & 1.19 & 0.83 & 2.24 & 1.03 \\
Reduction [\%] & 57 & 79 & 86 & 62 & 82 \\
\hline
\end{tabular}

while maintaining the same solidity, results in a higher damping of the velocity angle amplitude. Although the cases C.3 and C.5 have the same area reduction, the velocity angle damping in C.5 is $4 \%$ lower than C.3 that has a higher solidity. This higher damping caused by C.3 is achieved at the expense of 0.01 higher loss coefficient (see Fig. 6). It can be concluded that area reduction by either an increase of the solidity or the thickness to chord ratio plays a great role in velocity angle fluctuation damping.

To look into the details of the velocity angle downstream of the vanes in one RDC period, a box-and-whisker diagram of the measured data is plotted in Fig. 9b. In this plot, the first segment is the first quartile of the data. The second and third segments represent the difference between the median and the first quartile and the difference between the third quartile and the median respectively. The difference between the upper and lower limits of the whiskers shows the data range known as the velocity angle amplitude here, which has been already discussed in nondimensional form. According to the diagram, the median value is much closer to the whisker upper limit in C.3 and C.5 rather than the other cases. These two cases have the highest area reduction with different solidity and thickness to chord ratio. Although the thickness to chord ratio of case C.5 is two times greater than C.3, the higher solidity of C.3 compared to C.5 causes not only shorter range but also much steadier velocity angle downstream of the vanes. This can be also observed from the closer median value to the upper whisker limit. The median value is located at approximately mid of the box and whisker plots in other cases (C.1, C2 and C.4), which shows rather equally distributed values of the velocity angle in one RDC period.

To evaluate how the vanes affect total quantities downstream where rotor blades could be installed, time trace corrected total pressure $\left(\overline{P_{t}}=P_{t} / P_{t, \text { average@upstream }}\right)$ and total temperature $\left(\overline{T_{t}}=T_{t} / T_{t, \text { average@upstream }}\right)$ are calculated at $20 \% \mathrm{c}$ downstream of the vanes in one RDC time pe- 


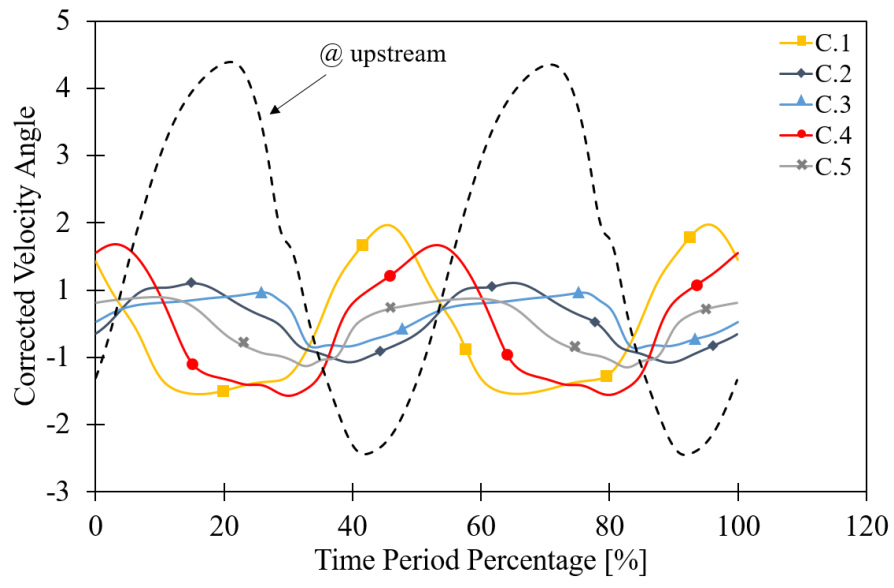

(a) Instantaneous distribution of corrected velocity angle

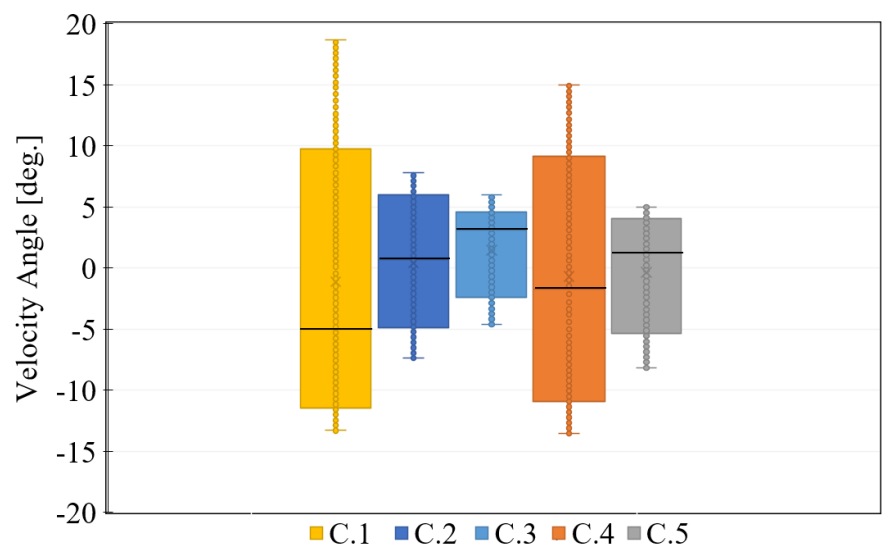

(b) Box and whisker diagram of measured velocity angle

Fig. 9: Velocity angle in one time period at $20 \%$ c downstream of the vanes.

riod. According to Fig. 10, increasing solidity corresponding to C.1, C.2 and C.3 exhibits smoother total pressure and total temperature distributions. The two local peaks observable on both curves of C.1 are moderated in C.2 and almost become smoothed in C.3. The same behavior can be seen by comparing C.1, C.4 and C.5. It indicates that a blade row with higher thickness to chord ratio has more damping effect on local unsteadiness of total pressure and total temperature. On the other hand, the curves of Fig. 10 show a rather slight difference in amplitude of the two total quantities distribution. The corrected amplitudes are listed in Tab. 3. Although local peaks get smoother by increasing area reduction, the fluctuation amplitudes of both total pressure and total temperature are increased. Additionally, the comparison of the total pressure amplitude at the inlet 


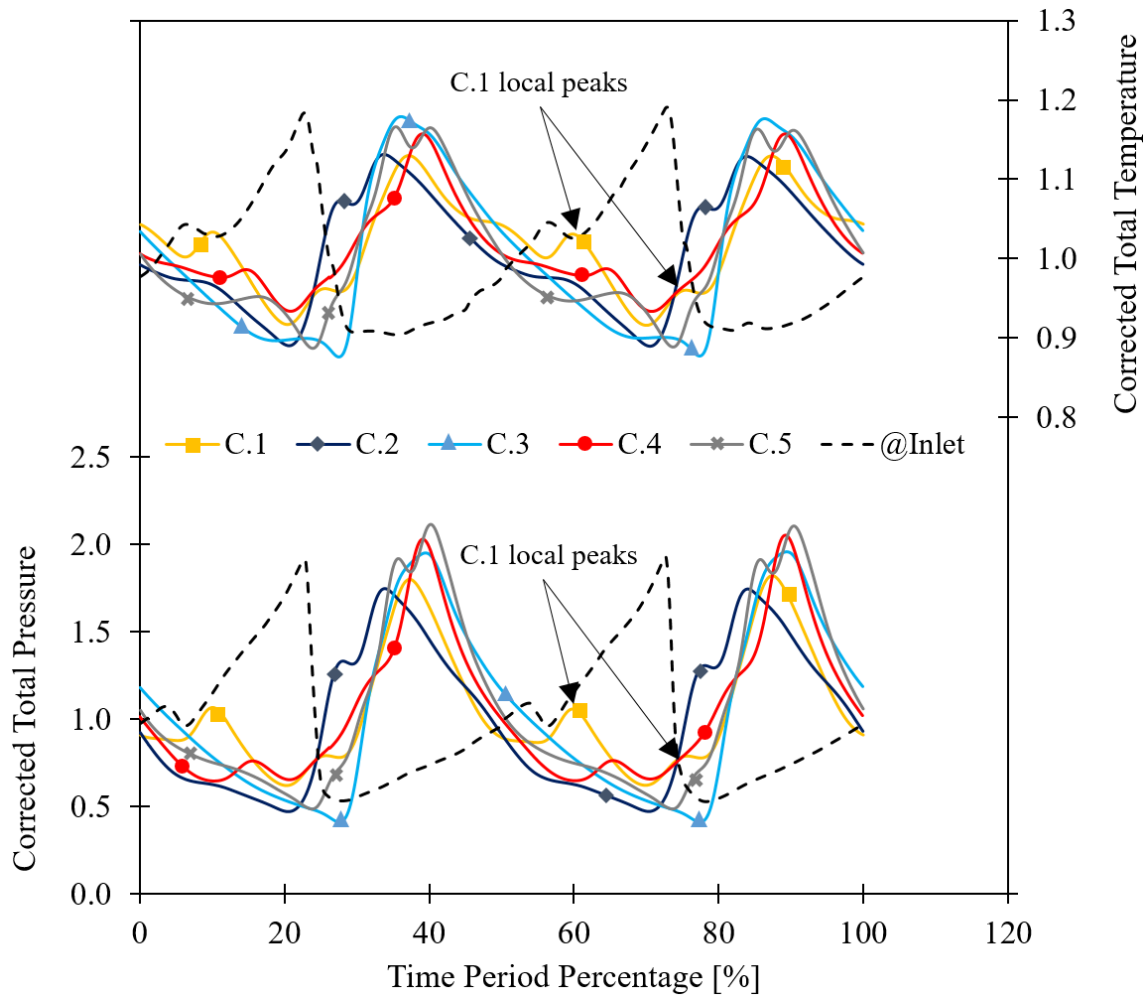

Fig. 10: Instantaneous distribution of total quantities at inlet and $20 \%$ c downstream of the vanes.

Table 3: Corrected total pressure and total temperature amplitude at inlet and $20 \% \mathrm{c}$ downstream of the vanes.

\begin{tabular}{ccccccc}
\hline \hline & C.1 & C.2 & C.3 & C.4 & C.5 & Inlet \\
\hline$\overline{A_{P_{t}}}$ & 1.2017 & 1.2771 & 1.5482 & 1.4075 & 1.6302 & 1.2210 \\
$\overline{A_{T_{t}}}$ & 0.2138 & 0.2415 & 0.3028 & 0.2236 & 0.2791 & 0.2866 \\
\hline
\end{tabular}

with the downstream reveals that $\mathrm{C} .1$ configuration damps total pressure fluctuation by $1.6 \%$ while the amplitudes at downstream of the other cases are higher than the inlet. The total temperature amplitude is alleviated from inlet to downstream for all the cases except C.3 which has the highest solidity. Despite the same area reduction of C.3 and C.5, total temperature damping role of these two configurations is different that confirms dominant impact of solidity. 
Journal of Engineering for Gas Turbines and Power

\section{CONCLUSION}

The present work focused on the aerodynamic behavior of different outlet guide vane configurations located downstream of an rotating detonation combustor. Numerical analysis was utilized as the method of investigation because it eliminates the difficulties and uncertainties of experiments within the high temperature RDC exhaust flow. Two dimensional URANS simulations have been performed to evaluate the effect of blade geometrical parameters on total pressure loss and velocity angle fluctuation damping. Five configurations with different solidity and thickness to chord ratio in the unwrapped combustor annulus have been modeled and simulated while one of them (C.1) has also been tested experimentally [19] and compared to the numerical simulation. Time and location dependent boundary conditions were imposed as the inlet boundary of the domain, which reproduces the two rotating waves operating mode of an RDC.

The results revealed that the total pressure loss coefficient in periodically steady flow field decreases by increasing each of the two geometrical parameters of solidity and thickness to chord ratio. This loss coefficient accounts profile loss caused by the vanes. However, in transient operation where moving strong shock waves are present downstream of the flow field, loss coefficient including shock loss and profile loss, increases by increasing solidity and thickness to chord ratio. It was shown that shock wave can add more than two times of blade profile loss to the flow field in transient operation. Choked flow condition was observed within the blades passages. Velocity angle measurements upstream and downstream of the vanes showed that more than $57 \%$ velocity angle fluctuation damping can be achieved by passing RDC exhaust flow through these vane configurations. Higher velocity angle damping was resulted by either increasing thickness to chord ratio or solidity, which means higher area reduction. However, in the configurations having the same area reduction and thickness to chord ratio, velocity angle damping was affected by solidity. Higher solidity configurations exhibit steadier velocity angle distribution in one RDC period. According to the studied configurations, it can be concluded that solidity had the highest impact on loss generation and total quantities distribution at downstream while area reduction was the most driving factor for velocity angle fluctuation damping. Future work will focus on other vane configurations. 


\section{ACKNOWLEDGEMENTS}

Elsa-Neumann Foundation (NaFöG) is gratefully acknowledged for financial support.

\section{REFERENCES}

[1] International Civil Aviation Organization, 2019. ICAO global environmental trends - Present and future aircraft noise and emissions.

[2] Popovíc, I., and Hodson, H. P., 2013. "Improving Turbine Stage Efficiency and Sealing Effectiveness Through Modifications of the Rim Seal Geometry". Journal of Turbomachinery, 135(6).

[3] Asli, M., and Mesgarpoor Tousi, A., 2013. "Performance analysis of axial flow compressor and part load consideration in a gas turbine application". Journal of Thermal Science and Technology, 8(3), pp. 476-487.

[4] Odgers, J., Kretschmer, D., and Pearce, G. F., 1993. "The Combustion of Droplets Within Gas Turbine Combustors: Some Recent Observations on Combustion Efficiency". Journal of Engineering for Gas Turbines and Power, 115(3), 07, pp. 522-532.

[5] Stathopoulos, P., 2018. "Comprehensive thermodynamic analysis of the humphrey cycle for gas turbines with pressure gain combustion". Energies, 11(12).

[6] Lu, F. K., and Braun, E. M., 2014. "Rotating Detonation Wave Propulsion: Experimental Challenges, Modeling, and Engine Concepts". Journal of Propulsion and Power, 30(5), pp. 11251142.

[7] Schauer, F., Bradley, R., and Hoke, J., 2003. "Interaction of a Pulsed Detonation Engine with a Turbine". In 41st AIAA Aerospace Sciences Meeting and Exhibit, no. January, pp. AIAA 2003-0891.

[8] Rasheed, A., Tangirala, V. E., Vadervort, C. L., Dean, A. J., and Haubert, C., 2004. "Interactions of a Pulsed Detonation Engine with a 2D Blade Cascade". Aiaa(January), p. 9.

[9] Rasheed, A., Furman, A. H., and Dean, A. J., 2011. "Experimental Investigations of the Performance of a Multitube Pulse Detonation Turbine System". Journal of Propulsion and Power, 27(3), pp. 586-596. 
[10] Wolański, P., 2015. "Application of the Continuous Rotating Detonation to Gas Turbine". Applied Mechanics and Materials, 782, pp. 3-12.

[11] Naples, A., Hoke, J., Battelle, R. T., Wagner, M., and Schauer, F. R., 2017. "RDE Implementation into an Open-Loop T63 Gas Turbine Engine”. In 55th AIAA Aerospace Sciences Meeting, no. January, American Institute of Aeronautics and Astronautics, pp. 1-9.

[12] Naples, A., Hoke, J., Battelle, R., and Schauer, F., 2019. "T63 Turbine Response to Rotating Detonation Combustor Exhaust Flow". Journal of Engineering for Gas Turbines and Power, 141(2).

[13] Rhee, H., Ishiyama, C., and Higashi, J., 2017. "Experimental Study on a Rotating Detonation Turbine Engine with an Axial Turbine". In 26th ICDERS, pp. 1-6.

[14] Tellefsen, J., 2012. "Build Up and Operation of an Axial Turbine Driven by a Rotary Detonation Engine". Msc thesis, Air Force Institute of Technology.

[15] Rankin, B. A., Hoke, J., and Schauer, F., 2014. "Periodic Exhaust Flow through a ConvergingDiverging Nozzle Downstream of a Rotating Detonation Engine". In 52nd Aerospace Sciences Meeting, American Institute of Aeronautics and Astronautics, pp. 1-12.

[16] Braun, J., Saavedra Garcia, J., and Paniagua, G., 2017. "Evaluation of the unsteadiness across nozzles downstream of rotating detonation combustors". 55th AIAA Aerospace Sciences Meeting(January), pp. 1-12.

[17] Liu, Z., Braun, J., and Paniagua, G., 2018. "Characterization of a Supersonic Turbine Downstream of a Rotating Detonation Combustor". Journal of Engineering for Gas Turbines and Power, 141(March), pp. 1-13.

[18] Braun, J., Cuadrado, D. G., Andreoli, V., Paniagua, G., Liu, Z., Saavedra, J., Athmanathan, V., and Meyer, T., 2019. "Characterization of an integrated nozzle and supersonic axial turbine with a rotating detonation combustor". In AIAA Propulsion and Energy 2019 Forum, no. August, American Institute of Aeronautics and Astronautics, pp. 1-11.

[19] Bach, E., Bohon, M., Paschereit, C. O., and Stathopoulos, P., 2018. "Development of an Instrumented Guide Vane Set for RDC Exhaust Flow Characterization”. In 2018 Joint Propulsion Conference, American Institute of Aeronautics and Astronautics. 
[20] Asli, M., Cuciumita, C., Stathopoulos, P., and Paschereit, C. O., 2019. "Numerical Investigation of a Turbine Guide Vane Exposed to Rotating Detonation Exhaust Flow". In Proceedings of the ASME Turbo Expo 2019, Volume 2B: Turbomachinery, American Society of Mechanical Engineers.

[21] Papa, F., Madanan, U., and Goldstein, R. J., 2017. "Modeling and Measurements of Heat/Mass Transfer in a Linear Turbine Cascade". Journal of Turbomachinery, 139(9), 04. 091002.

[22] Asli, M., and Tousi, A. M., 2011. "Sensitivity Analysis of a Centrifugal Compressor Using the Linearization Method". In ASME-JSME-KSME 2011 Joint Fluids Engineering Conference: Volume 1, Symposia - Parts A, B, C, and D, ASME, pp. 1785-1790.

[23] Menter, F. R., 1992. "Improved two-equation k-omega turbulence models for aerodynamic flows". NASA Technical Memorandum(103978), pp. 1 - 31.

[24] Greitzer, E., Tan, C., and Graf, M., 2004. Internal Flow: Concepts and Applications. Cambridge University Press.

[25] Chen, L., Zhuge, W., Zhang, Y., Xie, L., and Zhang, S., 2011. "Effects of Pulsating Flow Conditions on Mixed Flow Turbine Performance". In Turbo Expo: Power for Land, Sea, and Air, pp. 681-689.

[26] Kailasanath, K., 2013. "Rotating Detonation Engine Research at NRL". In International workshop on detonation for propulsion (IWDP 2013), pp. 1-14.

[27] Schwer, D. A., Brophy, C. M., and Kelso, R. H., 2018. "Pressure Characteristics of an Aerospike Nozzle in a Rotating Detonation Engine". In 2018 Joint Propulsion Conference, American Institute of Aeronautics and Astronautics, pp. 1-16.

[28] Aungier, R. H., 2006. Turbine Aerodynamics: Axial-Flow and Radial-Flow Turbine Design and Analysis. ASME, Three Park Avenue New York, NY 10016-5990, jan. 


\section{LIST OF FIGURES}

1 Schematic of the modeled RDC annulus with a nozzle blade row [19]. . . . . . . . 6

2 Computational domain and grid around the blades. . . . . . . . . . . . . . 7

3 Effect of grid size and time step on total pressure loss coefficient and mass averaged Mach number at $0.2 \mathrm{c}$ upstream of the vanes. . . . . . . . . . . . . . . 8

4 Total pressure distribution at upstream and downstream of the blade row. $\ldots . \ldots 9$

5 RDC exhaust flow properties considered as the inlet condition. . . . . . . . . . . 10

6 Total pressure loss coefficient. $\ldots \ldots \ldots \ldots \ldots$

7 Instantaneous contours of Mach number (left) and density (right) for C.4 . . . . . . . 14

8 Sonic condition inside the blade passages (a-e) and Mach number distribution for

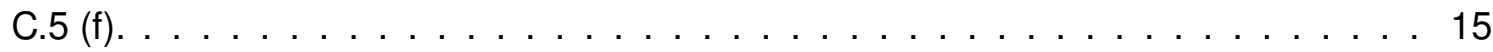

9 Velocity angle in one time period at $20 \%$ c downstream of the vanes. . . . . . . 17

10 Instantaneous distribution of total quantities at inlet and $20 \%$ downstream of the vanes. . . . . . . . . . . . . . . . . . . . . . 18 
Journal of Engineering for Gas Turbines and Power

\section{LIST OF TABLES}

1 Blade configuration specifications at RDC downstream. . . . . . . . . . . 11

2 Corrected velocity angle amplitude at $20 \%$ c downstream . . . . . . . . . . . . 16

3 Corrected total pressure and total temperature amplitude at inlet and $20 \%$ c down-

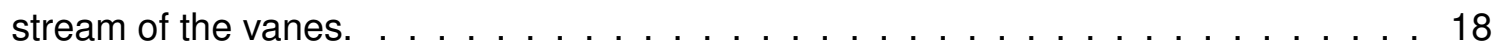

